\title{
O GRUPO ESCOLAR VISCONDE DE GUARAPUAVA: ESCOTISMO E ESCOLARIZAÇÃO DAS ATIVIDADES CORPORAIS NO INTERIOR DO PARANÁ (1920-1930)
}

Carlos Herold Junior

UNICENTRO

Alexandre Fernandez Vaz

UFSC

\section{RESUMO}

O objetivo deste trabalho é analisar a educação do corpo praticada pelo escotismo no interior do Grupo Escolar Visconde de Guarapuava, no período de 1920 e 1930. Utilizando-se de vários tipos de fontes primárias, priorizamos os jornais publicados na cidade para defender a seguinte hipótese: a conjugação da estrutura institucional do grupo escolar e das atividades escoteiras colaborou para a escolarização das atividades corporais e para a divulgação de modernidades pedagógicas no interior do Paraná. O texto foi dividido em duas partes: na primeira levantamos variáveis históricas de grande relevância para a história educacional de maneira geral: 1) o surgimento dos grupos escolares, 2) os debates sobre a educação física e 3) o surgimento do escotismo. Na segunda parte, analisamos essas variáveis no contex to do Grupo Escolar Visconde de Guarapuava.

Palavras-chave: Instituições escolares; Grupos Escolares; Guarapuava; Escotismo; Educação Física; Corpo.

\section{THE SCHOOL GROUP VISCONDE DE GUARAPUAVA: SCOUTING AND SCHOOLING OF BODY ACTIVITIES IN THE COUNTRYSIDE OF PARANÁ STATE}

\section{ABSTRACT}

The goal of this study is to analyze the body education practiced by Scouting within the Grupo Escolar Visconde de Guarapuava, between 1920 and 1930. Using several types of primary sources, we prioritized the newspapers published in the city to support the following hypothesis: the conjunction of the institutional structure of school group and Scout activities, contributed to the schooling of body activities and the dissemination of educational modernities in Paraná State. The text was divided into two parts: firstly, it raises historical issues of great importance for the history of education in general: 1) the emergence of school groups, 2) discussions on physical education and 3) the emergence of Scouting. In the second part, we analyze these issues in the context of Grupo Escolar Visconde de Guarapuava.

Keywords: School Institutions; School groups; Guarapuava; Scouting; Physical Education; body. 


\section{CONSIDERAÇÕES INICIAIS}

Ao completar seu centenário em 2012, o Colégio Estadual Visconde de Guarapuava possui 1141 alunos e 92 professores nos ensinos fundamental, médio e magistério (ESTADO DO PARANÁ, 2012). São os números mais recentes de uma instituição escolar que foi criada em 1912 como Grupo Escolar n.4 e que na década de 1920 passou a ser denominada Grupo Escolar Visconde Guarapuava. Em 1949, por meio do decreto 9161, tornou-se Escola de Aplicação Visconde de Guarapuava. Depois que a lei 5692/1971 veio a público, a instituição passou a ser Escola Visconde de Guarapuava - ensino regular e supletivo de 1. Grau. Em 1983, com a resolução n. 1118, a instituição passou a ser Escola Estadual Visconde de Guarapuava - Ensino de 1. grau regular e supletivo. Com a publicação da LDB 9396/1996, a instituição recebeu a denominação de Colégio Estadual Visconde Guarapuava - ensino fundamental e médio. É a partir de 2006 que a modalidade de magistério é incorporada à instituição, compondo, também, seu nome (COLÉGIO ESTADUAL VISCONDE DE GUARAPUAVA, 2010).

Essas "diferentes instituições" que se construíram no decorrer dos anos são representativas de muitos dos problemas e realizações educacionais da cidade. Em outro estudo (HEROLD JUNIOR, 2007) mostramos que as questões educacionais na história da cidade não vinham recebendo a devida atenção. No momento daquele levantamento Sarat (2004), Rocha (2005 e 2007) e Knüppel (2007 e 2008) eram exceções que se dedicaram, respectivamente, à infância na colônia Entre Rios, ao Colégio Nossa Senhora de Belém e à atuação do Professor João Becker e Silva no início do século XX.

Na tentativa de colaborar com o avanço dos estudos sobre a história da educação da cidade, desde 2007 conduzimos pesquisas que objetivam preencher algumas das lacunas temáticas observadas. Desse esforço, resultaram trabalhos que se debruçaram sobre as exigências educacionais e processos de modernização da cidade (AMARAL; HEROLD JUNIOR, 2010), as representações sobre a mulher e a institucionalização do ensino normal entre 1930 e 1960 (VICENTIN; HEROLD JUNIOR, 2012) e sobre o escotismo (HEROLD JUNIOR, 2011).

Tanto nos trabalhos que encontramos no levantamento que realizamos desde 2007, quanto nos textos redigimos a partir das pesquisas que temos conduzido, questões diretamente relacionadas ao Grupo Escolar Visconde de Guarapuava não receberam grande atenção. Apenas em um artigo sobre o escotismo na cidade (HEROLD JUNIOR, 2011) essa instituição aparece, ainda que secundariamente. Neste trabalho, aproveitando algumas sendas abertas pelos estudos anteriores, investigaremos, no contexto do Grupo Escolar Visconde Guarapuava, as relações entre o escotismo e a educação corporal escolarizada do corpo da infância e da juventude entre meados da década de 1920 até meados da década de 1930. Pretendemos demonstrar que a relação entre essa instituição escolar e as práticas formativas escoteiras foi de grande importância para realizar o processo de escolarização das atividades corporais praticadas pelas crianças da cidade. Essa escolarização era reivindicada pelos setores que absorviam as modernidades pedagógicas então em circulação no mundo, mas que em Guarapuava encontravam dificuldades para sua efetivação. Essas modernidades estavam presentes no contexto guarapuavano enquanto possibilidades de se contornar os problemas educacionais, sobretudo, ligados à falta de escolas e professores com condições de fazer a "pedagogia moderna" ser vista no dia a dia escolar.

A pesquisa que deu origem ao trabalho utilizou variada tipologia de fontes primárias. Todavia, para os fins deste artigo, detemo-nos nos jornais que circularam na cidade nas décadas de 1920 e 1930. Ao utilizá-los, endossamos as considerações de 
Schelbauer e Araujo (2007) que sublinham a importância desse tipo de impresso como fonte e objeto para análises em história da educação: "Se a educação é uma prática social que se estrutura a partir do que é veiculado pela cultura, a imprensa tem seu lugar na educação dos homens em sociedade" (SCHELBAUER; ARAÚJO, 2005, p.5).

As fontes primárias serão analisadas a partir das reflexões elaboradas por Justino Pereira de Magalhães relativas ao estudo histórico das instituições escolares. Para o estudioso português, as instituições escolares devem ser analisadas em três aspectos: materialidade, representação e apropriação (MAGALHÃES, 2005, p.96). Saviani (2007) explica que por materialidade, nos termos do tema por nós estudado, deve ser entendida como "escola instalada (instituído) em sua visibilidade mais imediata" (p.24); por representação a "materialidade-conteúdo enquanto antecipação ideal daquilo que deverá constituir a atividade própria da instituição" (p.25); e por apropriação a "materialidadeconteúdo em ato, compreendendo as práticas pedagógicas propriamente ditas mediante as quais se realizam as aprendizagens entendidas como incorporação do ideário pedagógico." (SAVIANI, 2007, p. 25).

Considerando o acima exposto, dividimos o texto em duas partes. Na primeira apresentamos questões que, ao existirem de forma universal, fizeram-se presentes no interior do Paraná e são importantes para nos ajudarem a entender a movimentação do Grupo Escolar Visconde de Guarapuava no período em tela. Na segunda, a partir de fontes primárias, verificamos como a materialidade, ideias, práticas e pessoas, que deram existência ao grupo escolar relacionaram-se para fazer com que o grupo e as práticas pedagógicas escoteiras, mutuamente, proporcionassem condições otimizadas para suas existências no interior do Paraná.

\section{1- O MUNDO NO GRUPO ESCOLAR VISCONDE DE GUARAPUAVA: GRANDES QUESTÕES PEDAGÓGICAS NO INÍCIO DO SÉCULO XX.}

A particularidade que caracteriza os problemas e o funcionamento do Grupo Escolar Visconde de Guarapuava não deve obscurecer que a delimitação das idiossincrasias sustenta-se na presença de grandes questões que eram discutidas em nível nacional e mundial e que se faziam sentir no cotidiano de muitas instituições daquele momento. Dentre as questões que nos permitem focalizar o funcionamento do Grupo Escolar Visconde de Guarapuava no interior do Paraná da década de 1920, elegemos como importantes três problemáticas: 1) a criação dos grupos escolares; 2) a escolarização das atividades corporais e 3 ) o desenvolvimento do escotismo e sua expansão pelo mundo a partir de 1907.

\subsection{Os grupos escolares a educação primária no início do século XX.}

O final do século XIX e início do século XX marcam um momento da história da educação caracterizado por variados esforços em escolarizar a sociedade. A criação dos sistemas nacionais de ensino nos países capitalistas avançados foi traço que impingiu desafios de grande dificuldade a quem pensava e fazia a educação que deveria, também, ser realizada para as classes populares e nas localidades afastadas dos grandes centros.

Ao lado das discussões filosóficas e políticas sobre o quê ensinar e a quem ensinar, bem como as dúvidas sobre quem financiaria os custos de tal empreitada, problemáticas pedagógicas surgiram para dar conta da nova e multiplicada demanda por educação. Para atender às novas expectativas formativas que surgiram nesse momento, os antigos modelos institucionais não serviam. Souza (2006, p.113) nota que na medida em que os grupos 
escolares passaram a ser vistos como a solução mais correta e racional para executar a nova missão educacional, as instituições representativas do velho modelo (as escolas isoladas e as escolas reunidas) passavam a ser alvo de grande descrédito.

O modelo institucional de grupos, existente em vários países europeus e também nos Estados Unidos, foi no Brasil posto em marcha inicialmente no Estado de São Paulo, em 1893. Os grupos escolares, nos anos que se seguiram, espalharam-se por vários Estados, sempre sob a ideia ser uma instituição que praticaria uma organização pedagógica livre dos problemas que eram observados na educação pública à época do Império. Bencostta (2005) observa que os grupos escolares representavam

\begin{abstract}
...um tipo de escola primária que pretendia ser moderna e diferente daquela existente no império: carente de edifícios, livros didático e mobiliário, precária em pessoal docente qualificado para o ensino de crianças e distante dos modernos métodos pedagógicos. Nesse sentido, para a recém-instalada república brasileira, a experiência inovadora das escolas primárias graduadas - ou grupos escolares, como vieram a ser denominados - foi entendida como um investimento que contribuiria para a consolidação de uma intencionalidade que procurava, por sua vez, esquecer a experiência do Império e apresentar um novo tipo de educação que pretendia ser popular a universal. (BENCOSTTA, 2005, p.69).
\end{abstract}

Souza (2007, p. 39) demonstra que essa insatisfação também existiu no Estado do Paraná, levando as autoridades a envidarem esforços para realizar o modelo dos grupos escolares, já existente no estado vizinho. A partir de 1903, os primeiros grupos surgem no contexto paranaense (OLIVEIRA, 2000). Em 1915, Francisco Ribeiro de Macedo assim justifica a importância dos grupos escolares para a educação paranaense:

Da organisação dos grupos e semigrupos advém naturalmente não só as grandes vantagens economico pedagogicas da divisão do trabalho e do maior resultado com menor esforço, mas ainda as vantagens pedagógicoadministrativas da fiscalisação directa ou indirecta que sobre os professores seus subordinados exerce constantemente o respectivo diretor (MACEDO, 1915, p.4).

Em Guarapuava, a expectativa que cercava os grupos escolares como instituições educacionais marcadas pela modernidade, também foi dirigida ao Grupo Escolar Visconde de Guarapuava, desde sua inauguração em 1912.

\title{
1.2 A escolarização das atividades corporais.
}

Discursos que afirmam o valor educacional das atividades corporais não foram novidades do final do século XIX e início do XX. Um olhar para a história do pensamento educacional relativo à educação corporal e à Educação Física, mostra que a prática de variadas atividades corporais com fito formativo foi uma atitude presente em várias sociedades (HEROLD JUNIOR, 2008).

A questão que se colocou como novidade desde o fim do século XIX foi o esforço para defender a importância dessas atividades na nascente escola pública, oferecendo práticas corporais pensadas como necessárias para todos. Se a dimensão formativa do esforço físico nunca deixou de ser algo desconsiderado pelos diferentes grupos dominantes 
que se sucederam na história, a questão que se colocava nos anos 1900 foi realizar essa mesma importância, também, para os filhos das classes trabalhadores.

Por conta dos desafios que se colocavam para concretizar tal ambição, uma grande quantidade de métodos, práticas e justificativas surgiram para endossar um olhar "racional" que bem selecionasse (escolarizasse) as atividades que deveriam fazer parte do ambiente educacional. Esse movimento de ideias e de proposições práticas também ocorreu em escala internacional, fazendo com que países com diferentes características culturais e possuidores de diferentes níveis de desenvolvimento econômico, defendessem ideias muito semelhantes entre si quando o assunto era a educação do e por meio do corpo (HEROLD JUNIOR e LEONEL, 2010).

De maneira geral, o ingresso das atividades corporais na escola passaria pelo crivo da ciência para que pudessem realizar fins educativos que propunham formar o cidadão e o trabalhador, fomentando atitudes condizentes com sociedades que se industrializavam.

$\mathrm{Na}$ defesa de práticas corporais que fossem educativas, muitas daquelas classificadas como impróprias pela impossibilidade de por meio delas se exercer controle, foram rechaçadas (BRUHNS, 1993). Nesse sentido, vale salientar a importância ginástica no início do século XX (AZEVEDO, 1915), assim como as críticas que o esporte ainda sofria como prática com finalidades educativas (MENDONÇA, 1921), antes de se tornar, no meio do século, o grande conteúdo das aulas de Educação Física (LINHALES, 2009).

\section{$1.3 \mathrm{O}$ surgimento e a expansão do Escotismo}

Procurar reunir crianças e jovens com a finalidade de fomentar valores por meio de atividades militares realizadas junto à natureza foi uma característica que marcou as inquietações educacionais na passagem para o século XX. Diversos agrupamentos surgiram, com denominações e características diferentes, mas sempre assumindo a necessidade de melhor educar a juventude, fazendo frente ao amolecimento dos jovens, que os "construtores de caráter" (MACLEOD, 1983) viam existir como resultado do progresso.

De particular interesse para o fortalecimento dessa preocupação era o clima bélico em que vivia o mundo durante a partilha imperialista que levou aos conflitos da Primeira Grande Guerra. Baden-Powell, fundador do escotismo, foi general participante de numerosos combates. A partir dessas experiências ele assumiu como importante a necessidade de melhor formar os homens para que eles suportassem não apenas o dia-a-dia da caserna, mas, principalmente, conseguissem assumir responsabilidades concernentes à pátria e ao trabalho quando não estivessem em campo de batalha.

Em 1907, amalgamando sua experiência militar com o conhecimento de outros grupos existentes, Baden-Powell fundou escotismo. Em 1908 ele publicou Scouting for Boys, que se tornou um dos primeiros sucessos editoriais do século XX (ROSENTHAL, 1986), estimulando uma expansão que tocou variados países com bases políticas, culturais e religiosas muito diferentes entre si.

No Brasil, o escotismo é iniciado em 1910 (BLOWER, 1994; NASCIMENTO 2008). No Paraná, em 1918 é publicado um regulamento da Associação Paranaense de Escoteiro, em que se sustenta o valor educacional do movimento. Esse valor para formação do jovem, entre outras coisas, aconteceria pela ênfase às atividades corporais: "Dá-lhe o exercicio physico, approximando-o o mais possivel da natureza, para que o moral puro, se desenvolva num corpo são (ASSOCIAÇÃO PARANAENSE DE ESCOTEIROS, 1918, p. 1). Essa passagem do regulamento sinaliza uma característica do escotismo que foi uma 
das responsáveis pela sua grande aceitação: o zelo pela educação corporal e, também, pela difusão de valores por meio de atividades corporais (HEROLD JUNIOR, 2011).

Souza (2009) e Gabriel (2003) mostram a inserção que o escotismo teve no processo de expansão escolar na década de 1920, ao vincular-se a uma pedagogia prática e atenta à saúde e ao patriotismo. O "escotismo escolar" é uma das características que marcam a história educacional do período. Focalizando a realidade paulista, mas com ideias também aplicáveis ao contexto paranaense, afirma Souza (2009, p. 269):

As inegáveis virtudes educativas do escotismo foram prontamente reconhecidas por intelectuais e educadores que passaram a defender sua introdução nas escolas públicas. De certa forma, o escotismo atualizava as expectativas da educação física e moral atribuída à matéria ginástica e exercícios militares introduzida no programa do ensino primário na primeira reforma republicana da instrução pública paulista.

Mesmo que a aceitação do escotismo no mundo escolar não tenha sido unânime entre os intelectuais e mesmo entre alguns dirigentes escoteiros, ele se fez presente no cotidiano de muitas instituições escolares do país. Em Guarapuava, a partir de 1928, as práticas escoteiras imprimiram um novo ritmo às atividades escolares, da mesma forma que o movimento foi impulsionado por acontecer no interior de um "templo da civilização", sendo essa a qualificação que Souza (1998) utiliza para estudar os Grupos Escolares nas primeiras décadas do século XX.

\section{MAZELAS E VIRTUDES PEDAGÓGICAS NO GRUPO ESCOLAR VISCONDE DE GUARAPUAVA.}

\section{$2.1 \mathrm{O}$ espaço, as pessoas e os discursos.}

O Grupo Escolar Visconde de Guarapuava, em 1928, possuía a 373 alunos (KNÜPPEL, 2007). Esse número sinaliza que ao analisarmos a história da educação guarapuavana durante a década de 1920, notamos a importância que o Grupo Visconde de Guarapuava teve para aqueles que pensavam e faziam a educação na cidade. Essa importância acontecia tanto para quem buscava enaltecer as conquistas educacionais, quanto para aqueles que observavam problemas a serem superados. Nessas duas maneiras de se olhar a educação em seu desenvolvimento, o Grupo Escolar Visconde de Guarapuava era criticado quando o assunto eram suas instalações, mas era elogiado quando nele se materializavam as esperanças formativas.

Esse era um padrão que, no entanto, nem sempre se concretizava. Durante as comemorações do centenário da Independência, o jornal $O$ Pharol publicou um encarte enaltecendo a data e, de certa maneira, tentou evidenciar a herança, a importância e a potencialidade de Guarapuava para o melhoramento do Paraná e do Brasil. Em um dos momentos de maior empolgação, o Grupo Escolar Visconde de Guarapuava é colocado em evidência, sobretudo pelo prédio em que estava instalado:

...no governo do Dr. Xavier da Silva, foi construído, nesta cidade, o predio do Grupo Escolar, onde passaram a funccionar as escolas publicas isoladas. Bom edificio, de estylo elegante, salas amplas, penetrando ahi ar em profusão e com os rigores da medicina escolar. Está situado em logar 
alto da cidade, dando ao edifico um bello aspecto (O PHAROL, 07/09/1922, p.4).

Em 1924, o Inspetor César Prieto Martinez não poupou elogios à região, afirmando o seguinte:

Guarapuava, cidade histórica e de grande fama, justifica o conceito em que é tida. Construida sobre o terceiro planalto, seis leguas da Serra da Esperança, a cidade antiga que recebeu a visita de Saint Hilaire e que assistiu as grandes luctas entre o branco e o gentio, que maravilhou os excursionistas de antanho e que despertou cobiças justificaveis, é a sede do maior município paranaense, maior talvez que a Belgica, um Estado dentro de outro Estado (MARTINEZ, 1924, p.90-91).

Entretanto, mais à frente, ao focalizar o Grupo Escolar Visconde Guarapuava, a posição do Inspetor é bastante desabonadora do funcionamento da instituição:

Encontrei o grupo (de Guarapuava) funccionando com três professores e o seu director, Snr. Antonio Tupy Pinheiro, auzente. A impressão que recebi não foi das melhores. Pequena matricula, apenas 100 alunos, dos quaes 85 eram presentes. $\mathrm{O}$ predio denotava certo abandono: portões de entrada, quebrados; quase todas as vidraças sem vidro; predio necessitoso de reformas e pinturas. [...] ...a Prefeitura Municipal estava tomando providencias no sentido de melhorar o predio escolar (MARTINEZ, 1924, p.230).

Por sua vez, Eurico Branco Ribeiro, em Coração do Paraná, oferece uma interessante análise da situação econômica, social, sanitária e escolar da cidade de Guarapuava. Ao focalizar a questão educacional por meio de um olhar sanitarista, o médico não economiza críticas. Partindo da dura constatação de que "Guarapuava sempre foi mal servida de escolas. [...]", reconhece que "Se em tempos possuiu estabelecimentos de ensino que se pode qualificar de modelares, a sua duração, porém, não foi grande, de modo que não deixaram tantos fructos quantos os que delles se podia esperar." (RIBEIRO, 1929, p. 61).

Depois disso a atenção do sanitarista volta-se para o grupo escolar então existente na cidade. Em razão de sua preocupação com a higiene, sublinha a instalação da instituição em um dos "recantos mais aprazíveis da localidade". Mas, em que pese o prédio ter sido construído "sob uma planta então adoptada systematicamente pela Inspectoria Geral do Ensino do Paraná", conclui que "O edifício não corresponde aos seus fins" (Ribeiro, 1929, p. 61). Para dar corpo à crítica, observa que a concepção do prédio deu-se com equívocos arquitetônicos que feriam disposições já conhecidas sobre como se pensar um espaço escolar que facilitasse o trabalho de ensino-aprendizagem:

Para se avaliar o que seja esse edificio sob o ponto de vista da hygiene escolar, basta dizer que na metade das salas os alumnos recebem luz pela direita e pelas costas, achando-se as llousas, em todas ellas, collocadas ao longo das paredes lateraes, sem ter despertado a menor preoccupação a incidência dos raios luminosos. Felizmente o governo do Estado reconheceu o erro e hoje não admitte mais a construcção de edifícios escolares do typo desse que ficará em Guarapuava para demonstrar, com 
prejuizos evidentes para as creanças que por alli passarem, a cegueira incompreensível de pretensos architectos do século presente (RIBEIRO, 1929, p.61-62).

Combinando com as concepções equivocadas que sustentaram a construção do prédio e que impediam o correto funcionamento da instituição, a limpeza era precária. Focalizar a situação dos banheiros foi uma estratégia para mostrar a necessidade de se considerar os preceitos básicos de higiene, necessários para se alcançar as justas ambições educacionais:

Se o edificio em si já apresenta inconvenientes, as installações defeituosas os multiplicam. Privadas, existem sómente duas, no pateo que circumda o predio, juntinha uma da outra, despejando ambas para a mesma fossa absorvente. O caixão de assento vive immundo; há papeis servidos por todos os cantos. E o interessante é que cada uma dellas é destinada a um sexo - duas unicamente para uma escola cuja matricula anda por 150 allunos! (RIBEIRO, 1929, p. 62).

Por fim, mesmo com a ênfase nas inadequadas condições arquitetônicas e higiênicas do grupo escolar, o médico nota o que seria ainda pior: "Mas não consiste, certamente, nas condições deploráveis do Grupo Escolar o grande desleixo dos poderes públicos pela instrucção em Guarapuava. O que mais avulta e prejudica o progreso do logar é a falta de escolas." (RIBEIRO, 1929, p. 62).

Outros registros analíticos desconsideravam, no entanto, os problemas arquitetônicos, assumindo aquele "espaço" como um lugar formativo de grande importância no fomento de valores patrióticos e civilizadores. O mesmo professor Antonio Tupy Pinheiro, criticado por Martinez em 1924 por estar ausente de suas funções durante a inspeção realizada, foi descrito como homem de grandes virtudes, dignas de um professor e diretor do Grupo Escolar Visconde de Guarapuava:

Filho da terra do Guayra, é possuidor de fina educação e intelligencia. Com sua Penna destrada, tem sabido attrair e enlevar o publico culta desta terra, com suas producções pedagógicas e de alta moral. O seu caracter sem nódoa, o mantem sempre, com altivez e dignidade. Director e prof. Do Grupo Escolar "Visconde de Guarapuava", transmite, com esclarecida competencia, ás creanças, que alli frequentam, os santos ensinamentos da escola . É nosso companheiro de redação (O PHAROL, 07/09/1922, p.12).

O fato de ser o diretor do Grupo Escolar e, também, "nosso companheiro de redacção", não é fato de menor valor para se considerar o jogo complexo entre a construção de uma determinada imagem pública da instituição e daqueles que nela trabalhavam. $\mathrm{O}$ fácil acesso à redação do jornal dava ao professor e diretor uma grande visibilidade que, ao mesmo tempo, era sustentada, ao mesmo tempo em que sustentava a importância do Grupo Escolar Visconde de Guarapuava na cidade. Por isso, ideias educacionais eram redigidas e publicadas, fazendo com que aquilo que se dizia praticar no interior da instituição fosse conhecido pelo público leitor de Guarapuava. Isso fica claro 
em um texto intitulado Heroismo Brasileiro, de autoria de Antonio Tupy Pinheiro, no qual lemos ideias que funcionavam como motes institucionais:

A raça brasileira sempre distingue-se pelo seu valor heroico, em todas as differentes especies das suas caracteristicas, componentes de um povo forte, energico e de iniciativas. O Brasil, presentemente, impõe-se pela sua educação physica, grandemente diffundida, fazendo da sua mocidade, uma fortaleza, que està de accordo com a pujança do nosso poderoso paiz. Alliada a esta esmerada educação está o principio admirável de energia, bravura e heroísmo, que alimentam e dão fibras superiores à nossa raça (O PHAROL, 07/09/1922, p.13).

A mesma postura é observada na descrição dos festejos que aconteceram na cidade, novamente no momento de comemoração do centenário da Independência. Por meio da voz do diretor e professor do Grupo Escolar Visconde Guarapuava e da publicação das palavras do "companheiro de redacção", observamos a importância de uma instituição escolar no processo de educação não apenas de seus alunos, mas de toda a comunidade. A plantação de uma árvore foi o motivo que simbolizou a oportunidade para se advertir sobre a relevância da educação:

Um dos festejos relativos ao centenário da independência foi o plantio de um pinheiro no pátio do Grupo Escolar Visconde de Guarapuava. No discurso, o diretor assim se expressou: "Este pinheirinho vae ser plantado aqui. O seu tronco altaneiro e recto é o fio a prumo da felicidade, o do futuro da grandiosa Patria Brasileira. As suas raízes marcam e symbolisam os nossos princípios democráticos profundos e fortemente arraigados na alma patriótica da nossa nacionalidade. Aqui plantado, elle se chamará a Arvore da Independencia, e ficarà nos chamando a attenção e nos dando saudades deste grande dia, ao mesmo tempo, que irá mostrar aos nossos descendentes o patriotismo brilhante deste povo, que sabe amar e honra a sua Patria. Meninas! Prestem bem atenção attenção e guardem nas suas almas toda a pureza e magnitude deste acto. As meninas, muito principalmente, precisam da educação cívica, porque o Brasil precisa de mães, que amanhã saibam ensinar aos seus filhos, este amor profundo, que se deve dedicar á Patria. Não se concebe e não se comprehende, Patria sem mães (O PHAROL, 07/09/1922, p.19).

A palavra pública que extrapolava as "paredes do prédio", alcançando mesmo aqueles que não participavam, diretamente, da instituição, endossa a ideia de terem sido os grupos escolares (SOUZA 1998), no geral, e o Grupo Escolar Visconde de Guarapuava, lugares de irradiação de mensagens patrióticas e civilizatórias que podiam ser ouvidas e lidas como "verdades". Foi nesse "lugar privilegiado" que o escotismo passou a funcionar em Guarapuava, a partir de 1928.

\subsection{Escotismo e escolarização das atividades corporais no grupo escolar.}

No dia 10 de Janeiro de 1928, o professor Amarilio Rezende de Oliveira enviou uma carta aos editores do jornal $O$ Pharol, avisando-lhes que tinha assumido a diretoria do Grupo Escolar Visconde de Guarapuava e da Escola Normal Complementar que lá funcionava (O PHAROL, 22/01/1928, p. 1). 
Iniciadas suas atividades como diretor do grupo escolar, Amarilio Rezende de Oliveira também fez uso intenso da imprensa local para divulgar suas ideias e as práticas pedagógicas que aconteciam na instituição. Notamos nos textos publicados pelo diretor, em primeiro lugar, um grande esforço em convencer a sociedade sobre a importância da instituição. Esse convencimento lutaria contra hábitos cotidianos de desconsideração ao funcionamento do grupo escolar que tocavam questões simples, como a pontualidade dos alunos para o início das atividades. Dependente dessa "boa educação" não estava apenas a grandeza de Guarapuava, mas a de todo o país. Em uma carta dirigida aos pais dos alunos, o diretor advertia:

É uma verdade acceita universalmente que, "sendo a escola a continuação do lar", o mestre, educador não pode - em absolucto - dispensar a cooperação do paes para cumprir a sua dupla missão de ensinar e educar. Assim sendo, e também por que estou convicto de que todos vós tendes uma aspiração: a felicidade de vossos filhos - peço-vos encarecidamente que elles sejam pontuaes e assíduos à escola. Da pontualidade e assiduidade ás aulas depende o aproveitamento dos vossos filhos. Cooperando, portanto, com os professores, promovereis não só o bem estar presente e futuro dos vossos filhos, como tambem recommendareis, sempre mais, aos poderes públicos o nome eo povo de Guarapuava, e, mais ainda, sereis todos apóstolos da patriótica campanha da instrucção e educação no Brasil (O PHAROL, 29/01/1928, p.1).

Essa atenção aos "pequenos hábitos de todo dia" justificava-se, pois "A escola sò é concebível como prolongamento do lar, assim como este deve ser uma escola em miniatura. Deste modo completam-se mutuamente" (O PHAROL, 26/02/1928). Ao lado desse esforço formativo voltado aos pais das crianças em idade escolar, o professor não descuidava de proporcionar aulas "nocturnas" que ocorreriam nas dependências do Grupo Escolar de Visconde de Guarapuava, para aqueles que não "não tiveram a felicidade de se instruir quando creanças". Afinal, ponderava Amarilio Resende de Oliveira, "O analphabeto è mais infeliz que o cègo" (O PHAROL, 29/01/1928, p.1).

Depois de dois meses como diretor e professor, Amarilio Rezende de Oliveira iniciou o processo de organização de um grupo escoteiro que funcionou na instituição $(\mathrm{O}$ PHAROL, 25/03/1928, p.1). Quase um mês após o anúncio dessa intenção, a criação do escotismo na cidade foi noticiada de maneira a valorizar a importância que ele teria para a integralidade da educação das crianças e dos jovens da cidade:

Foi hontem commemorada com brilho, a data que assignala o acontecimento mais glorioso da nossa historia. Com as festividades organisadas pelo esforçado director do nosso Grupo Escolar, coincidiu a organisação do Escoteirismo nesta cidade, instituição que visa fins nobilíssimos como a educação moral e physica da nossa juventude, preparando-a, animosa e forte, para as luctas de amanhã (O PHAROL, 22/04/1928, p.1).

A realização das práticas escoteiras no Grupo Escolar Visconde de Guarapuava deu-se depois de ampla divulgação das bases e das justificativas relativas ao valor do escotismo para a "regeneração da nossa raça depauperada". Essa "regeneração" era avaliada como uma "sagrada responsabilidade" que, para acontecer, deveria fazer frente a "todas resistências. E elas são muitas; ridículo, derrotismo, indifferença, oposições injustificáveis. A primeira é o ridículo em que os scepticos e derrotistas, os que duvidam 
de tudo e de todos, procuram corir toda "sublime aspiração"” (O PHAROL, 25/03/1928, p. 2). Perante forças tão intensas e danosas à "Pátria" e aos benefícios do "desígnio inabalável" de enaltecê-la, a resistência aconteceria por meio do Escotismo, visto como um "poderoso factor educativo". Dirigindo-se a todos que se "interessam pelo futuro do Brasil", escreve Amarilio Rezende de Oliveira:

O escoteirismo? Quem o desconhece hoje? De dia para dia, elle toma maior vulto entre nós por que todos reconhecem que o destino de nossa Patria, repousa no sucesso essa organisação. Só as gerações creadas nessa escola de energia, serão capazes de não se deixar vencer por esse amollecimento moral que abala e degrada as gerações de hoje. Entreguemo-nos pois com sinceridade e ardor ao Escoteirismo, certos de que prestamos ao paiz o maior serviço. Seremos nós os creadores da raça de amanhã. Homens, precisamos de homens! Homens de dever, homens de desinteresse e civismo, e é o Escoteirismo quem nol-os dará. É um cadinho de caracteres, é uma escola de dedicação, de altruísmo e desprendimento!O movimento é simples e está ao alcance de todos $(\mathrm{O}$ PHAROL, 25/03/1928, p. 2 e 4).

Toda essa projeção proporcionada pela palavra escrita nos jornais da cidade não foi suficiente para dar vazão ao ímpeto educacional existente no Grupo Escolar e nos seus escoteiros. Também em 1928, Amarilio Rezende de Oliveira funda o jornal Alerta!. Tratase de um periódico especificamente escoteiro em que matérias relativas às atividades do grupo eram publicadas ao lado de notícias e análises pertinentes ao Grupo Escolar Visconde de Guarapuava. Nesse jornal, vários são os exemplos de exortação dirigidos às crianças e aos jovens para que se comportassem corretamente no que diz repeito a sua saúde e a suas atitudes. Ser escoteiro significaria saber diferenciar o certo do errado, o que era posto nos seguintes termos:

Muitos meninos e jovens, suppõem que usar má linguagem, fumar, jogar, beber, entregar-se a actos e conversações immoraes, frequentar meios baixos, é prova de virilidade. Lastimável engano. Forte, viril, homem - é o menino e o jovem que tem o valor, a energia de se oppor a tão vergonhosos vícios (ALERTA!, 30/06/1929, p. 1).

Mesmo sendo especificamente escoteiro, o jornal Alerta! servia para a divulgação de ideias e atividades que extrapolavam atribuições do chefe escoteiro, chegando às de diretor do grupo escolar. O jornal foi espaço para Amarilio Rezende de Oliveira, entre outras coisas, convencer os pais da importância da Educação Física que dizia ser praticada na instituição:

Assim procedo para desfazer a aversão que muitos paes têm pela educação physica ministrada na escola. Alguns consideram os jogos, as excursões, o esporte, a gymnastica, enfim, todas as actividades que visam o desenvolvimento physico de seus filhos, uma entidade perigosa. (ALERTA! 21/07/1929, p. 1).

Além da divulgação de ideias pedagógicas modernas e que alcançavam a importância da Educação Física, observamos que a relação entre grupo escolar e escotismo se manifestava de outras formas. No dia 16/09/1929, o Alerta! explicava que durante o período de férias a sede do grupo escoteiro, localizada no interior do Grupo Escolar, 
poderia ser frequentada, também, pelos alunos da escola, mesmo que não pertencessem ao grupo escoteiro (ALERTA! 16/09/1929, p. 3). A ideia do diretor/chefe escoteiro era aproveitar corretamente o tempo livre das crianças e jovens com leituras e atividades corporais detentoras da correção e do potencial formativo existentes na escola e no grupo escoteiro.

Enfatizar a importância do escotismo para a boa condução da vida escolar era outra estratégia utilizada por Amarilio Rezende de Oliveira. Em uma tese apresentada na I Conferência Nacional de Educação, que aconteceu em Curitiba em 1927, o professor e, à época, futuro diretor de grupo escolar, já avaliava que as atividades escoteiras ajudariam a resolver problemas de comportamento e de disciplina dos alunos: "Por meio do escoteirismo, o professor consegue atrair as crianças e os jovens à escola, porque os jogos, os passeios e todas as diversões que o escoteirismo, muito de indústria, oferece, são um engodo milagroso para eles" (OLIVEIRA, 1997, p. 283). Observamos nessa ideia mais um motivo que explica a forte proximidade entre escotismo e instituições escolares que caracterizou uma parte relevante da história educacional brasileira do período.

\section{CONSIDERAÇÕES FINAIS}

Podemos observar a maneira complexa com que materialidade, representação e apropriação (MAGALHÃES, 2005) formam uma tríade de grande importância para pensarmos os problemas vivenciados pelo Grupo Escolar Visconde de Guarapuava e as esperanças que ele simbolizava ao ser conjugado com práticas educacionais escoteiras e sua ênfase nas atividades corporais.

Em Guarapuava muito do que havia de moderno em termos pedagógicos teve existência concreta materializada na reunião, em um mesmo espaço, do cotidiano de um grupo escolar com as atividades escoteiras de alguns de seus alunos. Igualmente importante observar é o fato de essa conjunção estar materializada na ação de Amarílio Rezende de Oliveira, diretor do grupo escolar, chefe escoteiro e divulgador de modernidades pedagógicas que eram debatidas nos grandes centros.

Não foi a intenção deste artigo enaltecer a instituição, o escotismo ou dirigente escolar que amalgamava práticas, espaços, discursos e representações que circulavam na imprensa local sobre as necessidades e os limites da educação então existente em Guarapuava. Estas reflexões encerram-se pretendendo ter demonstrado como a especificidade regional e institucional de um grupo escolar localizado no "coração do Paraná" (RIBEIRO, 1929) relacionou-se com ideias e práticas pedagógicas que cruzaram o Atlântico e se difundiram pelo país, evidenciando que as intenções educacionais mais importantes que davam a razão de ser das instituições educacionais, só se realizariam se elas contemplassem a prática e a escolarização das atividades corporais. Com efeito, no contexto guarapuavano, essa escolarização ganhou grande impulso com as atividades escoteiras que aconteceram no interior do Grupo Escolar Visconde de Guarapuava.

\section{REFERÊNCIAS}

ALERTA!, Guarapuava, n. 11, (30/06/1929) p. 1.

ALERTA ! Guarapuava, n. 13, (21/07/1929), p. 1.

ALERTA! Guarapuava. n. 9, (16/06/1929).p. 3. 
AMARAL, Mari Lúcia do; HEROLD JUNIOR, Carlos. Representações sobre a relação entre educação e modernização Guarapuava-PR entre 1930 e 1960. Revista Histedbr Online, Campinas, n. 38, p. 36-48, jun. 2010.

ASSOCIAÇÃO PARANAENSE DE ESCOTEIROS. Estatutos da Associação Paranaense de Escoteiros. Coritiba, 1918.

AZEVEDO, Fernando de. A poesia do corpo. Belo Horizonte : Imprensa Official do Estado de Minas, 1915.

BRUHNS, Heloisa Turini. O corpo parceiro e o corpo adversário. Campinas: Papirus, 1993.

BLOWER, Bernard David. História do escotismo brasileiro. Rio de Janeiro: Centro Cultural do Movimento Escoteiro, 1994.

COLÉGIO ESTAduAL VISCONDE DE GUARAPUAVA. Projeto Político Pedagógico. Guarapuava, $2010 . \quad$ Disponível em http://www.grpvisconde.seed.pr.gov.br/redeescola/escolas/14/950/1645/arquivos/File/PPP/ ppp_visconde_2012_14_02.pdf, Acesso em 27/03/2012.

BENCOSTTA, Marcus Levy Albino. Grupos escolares no Brasil: um novo modelo de escola primária. In: STEPHANOU, Maria; BASTOS, Maria Helena Camara (orgs.) Histórias e memórias da educação Brasil: Século XX. Petrópolis-RJ: Editora Vozes, 2005. p.68-76. v.III.

ESTADO DO PARANÁ. Consulta escolas. Disponível em http://www4.pr.gov.br/escolas/turma_matricula.jsp Acesso em 27/03/2012.

ESTADO DO PARANÁ. Consulta escolas. Disponível em http://www4.pr.gov.br/escolas/cpfuncional_regencia.jsp Acesso em 27/03/2012.

GABRIEL, Yara Cristina. Prescrições cívico-morais e a formação do cidadão: um estudo sobre a introdução do escotismo nas escolas públicas de São Paulo (1917-1922). Dissertação de mestrado, Mestrado em Educação: História, Política, Sociedade da PUCSP. São Paulo, 2003. 103p.

KNUPPEL, Maria Aparecida Crissi. Permanências e diversidades na constituição de um espaço escolar em Guarapuava (1910-1030). In: MACIEL, Margareth de Fátima et all. (orgs.). Educação e alteridade. Guarapuava/Irati: Unicentro, 2007. P.87-100.

KNUPPEL, Maria Aparecida Crissi. O movimento escolar militar no Paraná: ideias educativas de Juan Rodriguez Becker y Silva. VII CONGRESSO LUSOBRASILEIRO DE HISTÓRIA DA EDUCAÇÃO. Actas... Porto: Faculdade de Psicologia e Ciências da Educação (Universidade do Porto). p. 1-13, 2008. Disponível em:http://web.letras.up.pt/7clbheporto/trabalhos_finais/eixo1/IA2068.pdf Acesso em 21/08/2009. 
HEROLD JUNIOR, Carlos. Escolarização e instituições educacionais em Guarapuava: lançando as bases para um programa de pesquisa em história da educação. Revista HISTEDBR On-line, v. 28, p. 214-223, 2007. Disponível emhttp://www.histedbr.fae.unicamp.br/revista/edicoes/28/art14_28.pdf . Acesso em 20/03/2009.

HEROLD JUNIOR, Carlos. A educação corporal no Paraná através do movimento escoteiro em Guarapuava (1927-1936). Educ. rev., Belo Horizonte, v. 27, n. 2, Aug. Available from <http://www.scielo.br/scielo.php?script=sci_arttext\&pid=S010246982011000200007\&lng=en\&nrm=iso>. access on 11 Apr. 2012.

HEROLD JUNIOR, Carlos; LEONEL, Zélia. A educação física e a criação dos sistemas nacionais de ensino: da prática social à pratica escolar. Maringá: Eduem, 2010.

LINHALES, Meily Assbú. A escola e o esporte: uma história de práticas culturais. São Paulo: Cortez, 2009.

MACLEOD, David. Building Character in the american boy: the boy scouts, YMCA, and their forerunners, 1870-1920. London: The University of Wisconsin Press, 1983.

MACEDO, Francisco Ribeiro de Azevedo. Relatório apresentado ao cidadão Dr. Claudino Rogoberto Ferreira dos Santos. Curitiba: Typ. do Diario Official, 1915.

MAGALHES, Justino. A história das instituições educacionais em perspectiva. In: GATTI JUNIOR, Décio; Geraldo Inácio Filho (orgs.). História da educação em perspectiva: ensino, pesquisa, produção e novas investigações. Campinas-SP: Autores Associados. Uberlândia-MG: EDUFU, 2005. p.91-104.

MARTINEZ, Cesar Prieto. Relatório apresentado ao Exmo. Sr. Dr. Secretario Geral de Estado. Curityba: Typ. da Penitenciaria do Estado, 1924.

MENDONÇA, Carlos Süssekind de. O Sport está deseducando a mocidade brasileira: carta aberta a Lima Barreto. Rio de Janeiro: Empreza Brasil Editora, 1921.

NASCIMENTO, Jorge Carvalho do. A escola de Baden-Powell: cultura escoteira, associação voluntária e escotismo de estado no Brasil. Rio de Janeiro: Imago, 2008.

OLIVEIRA, Maria Cecília. O grupo escolar dezenove de dezembro: história e organização. In: Congresso Brasileiro de História da Educação: Educação no Brasil: História e Historiografia...ANAIS. Rio de Janeiro: UFRJ, 2000.

O PHAROL. Guarapuava, n.129, 07/09/1922, anno IV.

O PHAROL. Guarapuava, n.144, 22/01/1928 ano VI.

O PHAROL. Guarapuava, n.145 29/01/1928, anno VI.

O PHAROL. Guarapuava, n. 148, 26/02/1928, anno VI. 
O PHAROL. Guarapuava, n.152, 25/03/1928, anno VI.

O PHAROL. Guarapuava, n.156, 22/04/1928, anno VI.

RIBEIRO, Eurico Branco. O coração do Paraná: estudo sanitário. São Paulo: São Paulo Editora, 1929.

ROCHA, Rita de Cássia Luis. Imprensa, Educação e Civilidade. In: IX Simpósio Internacional Processo Civilizador: Tecnologia e Civilização, 2005, Ponta Grossa. Anais ... IX Simpósio Internacional Processo Civilizador: Tecnologia e Civilização, 2005.

ROCHA, Rita de Cássia Luis. da. Educação e civilidade: o discurso da ordem missionária servas do espírito santo (1907 - 1955). Dissertação. Mestrado em Educação. Unimep, 2007.

ROSENTHAL, Michael. The character factory: Baden-Powell and the origins of the boy scout movement. London: Collins, 1986.

SARAT, Magda. Histórias de Estrangeiros: infância, memória e educação. Tese de Doutorado. Universidade. Metodista de Piracicaba/UNIMEP, Piracicaba/SP, 2004.

SAVIANI, Dermeval. Instituições escolares no Brasil: conceito e reconstrução histórica. In: NASCIMENTO, Maria Isabel Moura et all. (orgs.) Instituições escolares no Brasil: conceito e reconstrução histórica. Campinas-SP: Autores Associados, 2007. p.3-30.

SCHELBAUER, Analete Regina; ARAÚJO, José Carlos Souza (Orgs.). História da educação pela imprensa. Campinas, SP: Alínea, 2007.

SOUZA, Rosa Fátima de. Templos de civilização: a implantação da escola primária graduada no Estado de São Paulo (1890-1910). São Paulo:UNESP, 1998.

SOUZA, Rosa Fátima de Souza. Lições da escola primária. In: SAVIANI, Dermeval et all. (orgs) O legado educacional do século XX no Brasil. 2.ed. Campinas-SP: Autores Associados, 2006. p.109-161.

SOUZA, Rosa Fátima de. Alicerces da Pátria: história da escola primária no Estado de São Paulo (1890-1976). Campinas - SP: Mercado das Letras, 2009.

SOUZA, Gisele. Cultura material escolar na história da educação pública primária do Paraná, Revista Brasileira de História da Educação. n.14, maio/ago 2007. p.37-68. Disponível em http://www.sbhe.org.br/novo/rbhe/RBHE14.pdf Acesso em 10/04/2012.

VICENTIN, Sonia Antonovicz.; HEROLD JUNIOR, Carlos. O corpo da docência: a mulher e a constituição do ensino normal em Guarapuava (1930-1960). 1. ed. Guarapuava/Curitiba: Edunicentro/Fundação Araucária, 2012.

Recebido em: $\quad 05.05 .12$

Aprovado em: $\quad 30.05 .12$ 